\title{
Phylogenetic Analysis of Species of the meso-Diaminopimelic Acid-Containing Genera Brevibacterium and Dermabacter
}

\author{
JUNPENG CAI AND MATTHEW D. COLLINS* \\ Institute of Food Research, Reading Laboratory, Earley Gate, Reading RG6 2EF, United Kingdom
}

\begin{abstract}
16S rRNA gene sequencing studies were performed on Dermabacter hominis and four meso-diaminopimelic acid-containing species of the genus Brevibacterium. Phylogenetic analysis revealed a close association between Dermabacter hominis and representatives of the lysine-containing genera Arthrobacter, Micrococcus, and Renibacterium. By contrast, the genus Brevibacterium formed a distinct line of descent within the high-guanineplus-cytosine-containing actinomycetes, displaying no specific affinity with any other organism examined.
\end{abstract}

The genus Brevibacterium was created by Breed (1), with Brevibacterium linens as the type species, for a diverse group of gram-positive, short, nonbranching, rod-shaped bacteria. For a number of years the taxonomy of the genus was unsatisfactory, with species displaying a range of different phenotypes. In 1980 the genus Brevibacterium was redefined (3) primarily on the basis of chemotaxonomic criteria and restricted to the mycolic acid-less, meso-diaminopimelic acid (wall type $m$ - $\mathrm{A}_{2} \mathrm{pm}$-direct)-containing species Brevibacterium linens and Brevibacterium iodinum. Two additional species, Brevibacterium casei and Brevibacterium epidermidis, were subsequently assigned to the genus (2). More recently, Jones and Collins (7) described a new genus, Dermabacter, for some gram-positive asporogenous rod-shaped diphtheroids from human skin. Chemotaxonomically, Dermabacter hominis resembles species of the genus Brevibacterium in lacking mycolic acids and in containing cell walls based on $m-\mathrm{A}_{2} \mathrm{pm}$ (7). Dermabacter hominis, however, differs physiologically from brevibacteria in being facultatively anaerobic and in producing acid from glucose and other sugars in peptone media (7). 16S rRNA cataloging studies (11) have shown that the type species of the genus Brevibacterium, Brevibacterium linens, forms a distinct line of descent within the high-guanine-plus-cytosine-containing gram-positive bacteria. To date, however, there is no information on the phylogenetic position of other members of the genus (viz., Brevibacterium casei, Brevibacterium epidermidis, and Brevibacterium iodinum) or on the amycolate, $m-\mathrm{A}_{2} \mathrm{pm}$ wall-containing species Dermabacter hominis. Therefore, in order to investigate the phylogenetic affinities of these taxa, we have determined their almost complete $16 \mathrm{~S}$ rRNA gene sequences.

Chromosomal DNA was prepared from Dermabacter hominis NCFB $2769^{\mathrm{T}}$, Brevibacterium casei NCDO $2048^{\mathrm{T}}$, Brevibacterium epidermidis NCDO $2286^{\mathrm{T}}$, Brevibacterium iodinum NCDO $613^{\mathrm{T}}$, and Brevibacterium linens NCDO 739 as described by Lawson et al. (9). 16S rRNA genes were amplified by PCR and sequenced directly with the Sequenase version 2.0 sequencing kit (U.S. Biochemicals) as described previously (6). Sequences were aligned and percent similarities were determined with the Wisconsin Molecular Biology package (5). Phylogenetic trees were constructed by the neighbor-joining (NJ) method (10) using bootstrap values obtained with the NJ-BOOT program.

The 16S rRNA gene sequences consisted of 1,438 to 1,482 nucleotides corresponding to 93 to $96 \%$ of the full 16S rRNA primary structure. Approximately 1,320 nucleotides of each of these sequences (ranging from positions 107 to 1427; Esche-

* Corresponding author. Phone: (734) 357226. Fax: (734) 267917. richia coli numbering system) were aligned with those of other high-guanine-plus-cytosine-containing gram-positive organisms available from the EMBL data library, and sequence similarities were calculated (Table 1). It was evident from the sequence analysis that all four members of the genus Brevibacterium were highly related to each other (approximately 97 to 99\% similarity) and that they form a distinct phylogenetic grouping. The degree of sequence similarity with other organisms examined was not higher than $90.5 \%$ (Table 1). The treeing program and bootstrap calculations confirmed these

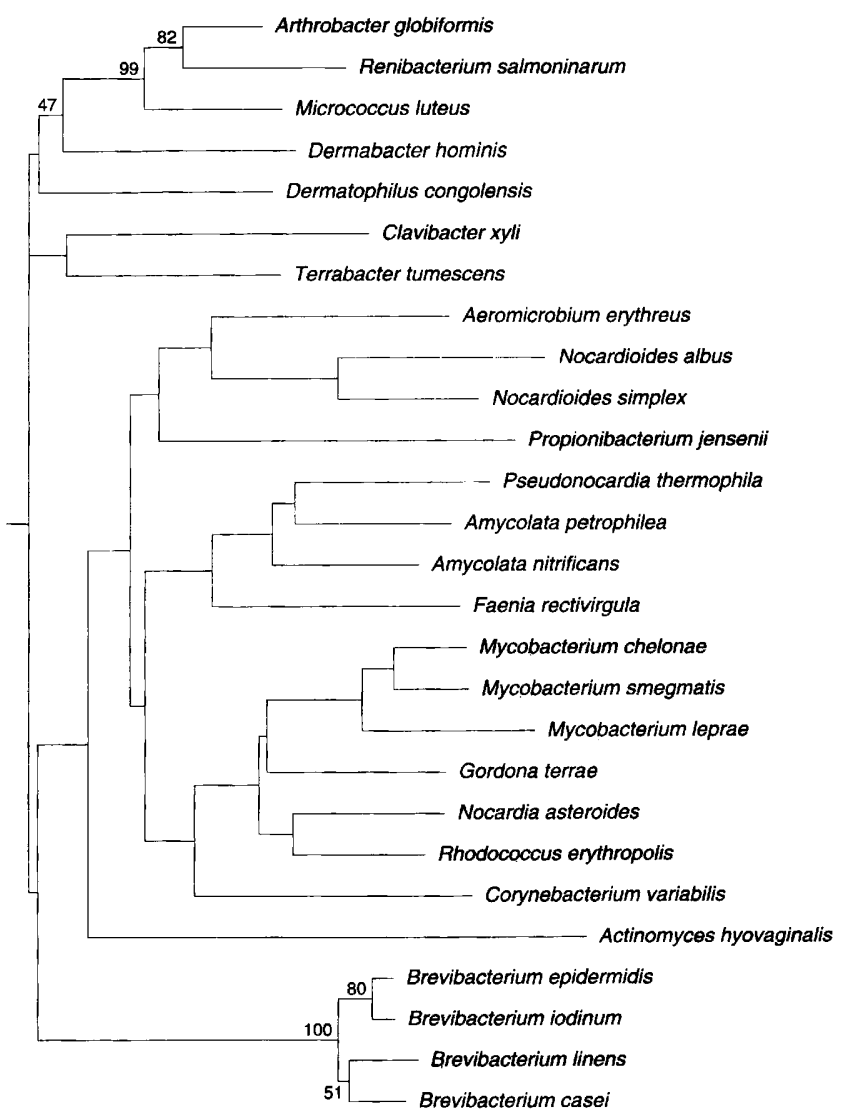

FIG. 1. Phylogenetic tree constructed by the NJ method showing the interrelationships of species of the genera Brevibacterium and Dermabacter and other representative high-guanine-plus-cytosine-containing gram-positive bacteria. Bootstrap values are indicated at branching points. 
TABLE 1. Representative 16S rRNA sequence similarities of Dermabacter hominis, Brevibacterium spp., and other high-G $+\mathrm{C}$ gram-positive bacteria

\% 16S rRNA similarity of:

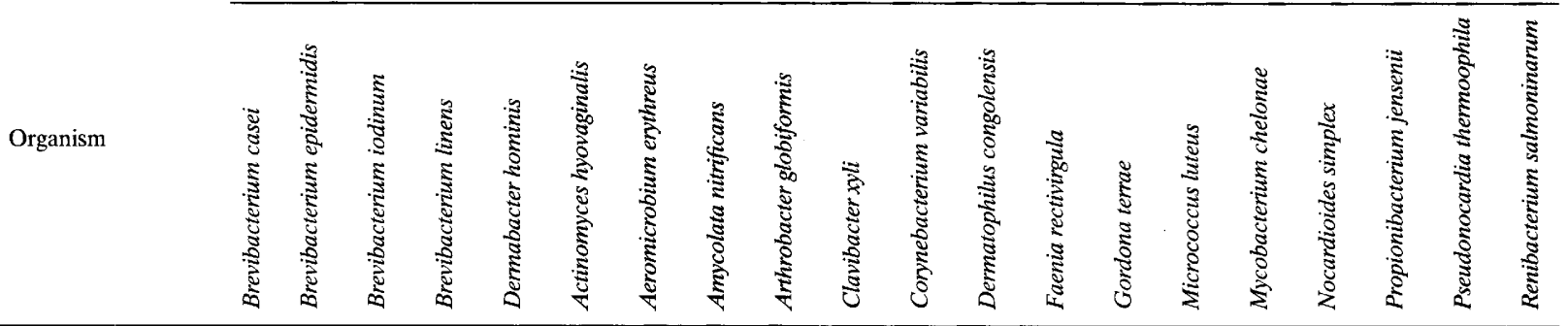

Brevibacterium casei Brevibacterium epidermidis Brevibacterium iodinum Brevibacterium linens Dermabacter hominis Actinomyces hyovaginalis Aeromicrobium enthreus Amycolata nitrificans Arthrobacter globiformis Clavibacter xyli Corynebacterium variabilis Dermatophilus congolensis Faenia rectivingula Gordona terrae Micrococcus luteus Mycobacterium chelonae Nocardioides simplex Propionibacterium jensenii Pseudonocardia thermophila Renibacterium salmoninarum

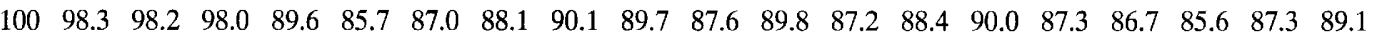
$\begin{array}{lllllllllllllllllll}100 & 99.4 & 97.4 & 89.4 & 85.9 & 87.5 & 88.6 & 90.4 & 89.0 & 88.0 & 89.8 & 87.5 & 89.1 & 90.1 & 88.1 & 86.7 & 86.2 & 87.5 & 89.6\end{array}$ $\begin{array}{llllllllllllllllll}100 & 97.8 & 89.8 & 85.6 & 87.5 & 88.3 & 90.4 & 89.0 & 87.9 & 90.4 & 87.2 & 88.8 & 90.1 & 87.8 & 86.6 & 86.0 & 87.4 & 89.6\end{array}$ $\begin{array}{llllllllllllllllll}100 & 89.8 & 85.6 & 87.0 & 87.7 & 90.1 & 88.8 & 87.5 & 90.3 & 86.5 & 88.5 & 89.7 & 86.9 & 85.8 & 85.8 & 87.2 & 91.5\end{array}$ $\begin{array}{llllllllllllllll}100 & 87.9 & 88.1 & 90.4 & 93.0 & 89.8 & 88.3 & 92.6 & 89.0 & 86.4 & 93.1 & 87.6 & 87.6 & 87.8 & 87.7 & 91.5\end{array}$ $\begin{array}{llllllllllllllll}100 & 86.0 & 88.0 & 87.0 & 85.1 & 86.2 & 87.2 & 86.6 & 86.1 & 86.7 & 86.3 & 85.5 & 85.8 & 86.8 & 85.8\end{array}$ $\begin{array}{llllllllllllll}100 & 90.6 & 90.5 & 89.5 & 89.2 & 89.8 & 89.6 & 89.6 & 89.8 & 90.1 & 91.4 & 90.1 & 88.7 & 89.0\end{array}$ $\begin{array}{lllllllllllll}100 & 89.7 & 89.2 & 89.0 & 90.7 & 91.7 & 90.6 & 90.5 & 91.2 & 90.6 & 89.7 & 93.9 & 88.2\end{array}$ $\begin{array}{llllllllllll}100 & 91.4 & 90.1 & 92.6 & 88.8 & 89.6 & 96.3 & 89.7 & 89.4 & 88.9 & 88.1 & 96.1\end{array}$ $\begin{array}{lllllllllll}100 & 86.7 & 90.7 & 88.4 & 88.1 & 91.5 & 86.6 & 89.8 & 87.1 & 87.0 & 87.0\end{array}$ $\begin{array}{llllllllll}100 & 90.3 & 89.2 & 91.7 & 89.9 & 90.6 & 87.6 & 88.0 & 88.4 & 89.0\end{array}$ $\begin{array}{lllllllll}100 & 88.3 & 89.5 & 91.9 & 88.8 & 89.1 & 87.9 & 89.6 & 92.0\end{array}$ $\begin{array}{llllllll}100 & 91.1 & 89.5 & 90.3 & 89.3 & 89.1 & 93.3 & 87.4\end{array}$ $\begin{array}{lllllll}100 & 89.2 & 94.3 & 90.1 & 89.4 & 90.5 & 88.6\end{array}$ $\begin{array}{llllll}100 & 89.3 & 88.4 & 89.0 & 87.9 & 94.3\end{array}$ $\begin{array}{lllll}100 & 89.6 & 89.0 & 91.0 & 87.8\end{array}$ $\begin{array}{llll}100 & 88.5 & 88.7 & 87.1\end{array}$ $\begin{array}{lrr}100 \quad 87.0 & 88.0\end{array}$ $100 \quad 87.2$ 100 findings and demonstrate that brevibacteria represent an individual line of descent, at a phylogenetic distance from all other reference actinomycetes that excludes a close relationship at the genus level (Fig. 1). By contrast, from the pairwise analysis Dermabacter hominis displays high sequence similarity to $\mathrm{Ar}$ throbacter globiformis (93.0\%), Micrococcus luteus (93.1\%), and Renibacterium salmoninarum $(91.5 \%)$. Significantly lower sequence relatedness values were shown with other taxa examined (generally less than 90\%) (Table 1). Figure 1 shows a tree constructed from calculated evolutionary distances by the NJ method that reinforces the affinity between Dermabacter hominis and the Arthrobacter/Micrococcus subline. From a phenotypic point of view the phylogenetic relationship between Dermabacter hominis and the genus Arthrobacter and its relatives is surprising because the former species contains a cell wall based on $m-\mathrm{A}_{2} \mathrm{pm}$ (7). Members of the Arthrobacter/ Micrococcus subline invariably contain cell walls with L-lysine as the dibasic amino acid (8). The genus Arthrobacter is known to be chemotaxonomically very heterogeneous $(4,8)$, and additional sequences are clearly necessary before the precise position of Dermabacter hominis within this subline can be established with confidence. However, from the limited sequence data available it is evident that the association between Dermabacter hominis and the Arthrobacter/Micrococcus subline is not a particularly close one (Fig. 1). It therefore seems likely that Dermabacter hominis is genetically sufficiently distinct from Arthrobacter sensu stricto (Arthrobacter globiformis and closely related species) to justify its separate generic status.

Nucleotide sequence accession numbers. The 16S rRNA gene sequences have been deposited in GenBank under acces- sion numbers X76728 (Dermabacter hominis), X76564 (Brevibacterium casei), X76565 (Brevibacterium epidermidis), X76566 (Brevibacterium linens), and X76567 (Brevibacterium iodinum).

This work was funded by a grant from the Ministry of Agriculture, Fisheries and Food.

\section{REFERENCES}

1. Breed, R. S. 1953. The Brevibacteriaceae fam. nov, of order Eubacteriales. Riass Commun. 6th Congr. Int. Microbiol. Roma 1:10-15.

2. Collins, M. D., J. A. E. Farrow, M. Goodfellow, and D. E. Minnikin. 1983. Brevibacterium casei sp. nov. and Brevibacterium epidermidis sp. nov. Syst. Appl. Microbiol. 4:388-395.

3. Collins, M. D., D. Jones, R. M. Keddie, and P. H. A. Sneath. 1980. Reclassification of Chromobacterium iodinum (Davis) in a redefined genus Brevibacterium (Breed) as Brevibacterium iodinum nom. rev.; comb. nov. J. Gen. Microbiol. 120:1-10.

4. Collins, M. D., and R. M. Kroppenstedt. 1983. Lipid composition as a guide to the classification of some coryneform bacteria containing an A4 $\alpha$ type peptidoglycan. Syst. Appl. Microbiol. 4:95-104.

5. Devereux, J., P. Haeberli, and O. Smithies. 1984, A comprehensive set of sequence analysis programs for the VAX. Nucleic Acids Res. 12:387-395.

6. Hutson, R. A., D. E. Thompson, and M. D. Collins. 1993. Genetic interrelationships of saccharolytic Clostridium botulinum types B, $\mathrm{E}$ and $\mathrm{F}$ and related clostridia as revealed by small-subunit rRNA gene sequences. FEMS Microbiol. Lett. 108:103-110.

7. Jones, D., and M. D. Collins. 1988. Taxonomic studies on some human cutaneous coryneform bacteria: description of Dermabacter hominis gen. nov., sp. nov. FEMS Microbiol. Lett. 51:51-56. 
8. Jones, D., and R. M. Keddie. 1992. The genus Arthrobacter, p. 1283-1299. In A. Balows, H. G. Trüper, M. Dworkin, W. Harder, and K. H. Schleifer (ed.), The prokaryotes, vol. II. SpringerVerlag, New York.

9. Lawson, P. A., S. E. Gharbia, H. N. Shah, and D. R. Clark. 1989. Recognition of Fusobacterium nucleatum subgroups Fn-1, Fn-2 and $\mathrm{Fn}-3$ by ribosomal RNA gene restriction patterns. FEMS
Microbiol. Lett. 65:41-46.

10. Saitou, N., and M. Nei. 1987. The neighbor-joining method: a new method for reconstructing phylogenetic trees. Mol. Biol. Evol. 4:406-425.

11. Stackebrandt, E., B. J. Lewis, and C. R. Woese. 1980. The phylogenetic structure of the coryneform group of bacteria. Zentralbl. Bakteriol. Mikrobiol. Hyg. Abt. 2 Orig. C1:137-149. 